\title{
Digital transformation in entrepreneurship education centres: preliminary evidence from the Italian Contamination Labs network
}

\author{
Giustina Secundo \\ Department of Engineering for Innovation, University of Salento, Lecce, Italy and \\ University of Salento, Lecce, Italy \\ Pierluigi Rippa \\ Department of Industrial Engineering, University of Naples Federico II, \\ Napoli, Italy, and \\ Michele Meoli \\ Department of Management, \\ Information and Production Engineering, University of Bergamo, Bergamo, Italy
}

Entrepreneurship education centres

Received 1 November 2019 Revised 24 March 2020 Accepted 25 April 2020

\begin{abstract}
Purpose - This paper analyses whether the entrepreneurship education centres introduced by the Italian Ministry of Higher Education and Research in 2012 (the Italian Contamination Labs - CLabs) are effectively adopting the emergent digital technologies for nurturing their entrepreneurship education activities and dissemination of knowledge contamination practices among university students.

Design/methodology/approach - An in-depth analysis of italian entrepreneurship education centres provides evidence about the direct role played by digital technologies in supporting and enhancing the entrepreneurial processes, as well as on their indirect role in stimulating entrepreneurship activities of nascent student entrepreneurs.

Findings - Findings provide some insights into the strategic role of some categories of digital technologies inside the CLabs. The main results show still a weak use of digital technologies in CLabs except for social media and digital platforms, mainly used for promotion scope and communication of the entrepreneurial outputs achieved by the students.

Research limitations/implications - Limitations of the study consist of the need to expand the study to all the other CLabs belonging to the CLabs Italian Network and to derive a set of "invariance" among the cases in terms of digital technologies support for student entrepreneurship.

Practical implications - New ways of managing entrepreneurship centres will involve a more massive adoption of digital technologies to support and transform some processes realized inside the CLabs, even if the governance of such centres must develop new digital skills.
\end{abstract}

(C) Giustina Secundo, Pierluigi Rippa and Michele Meoli. Published by Emerald Publishing Limited. This article is published under the Creative Commons Attribution (CC BY 4.0) licence. Anyone may reproduce, distribute, translate and create derivative works of this article (for both commercial and noncommercial purposes), subject to full attribution to the original publication and authors. The full terms of this licence may be seen at http://creativecommons.org/licences/by/4.0/legalcode

This research received the Contamination Lab's project funding. Programma Nazionale per la Ricerca 2015-2020 - Avviso per la presentazione di progetti Contamination LAB di cui al D.D. Miur n. 3158 del 29/11/2016 - Progetto Contamination Lab prot. n. CL16CWFNBS - Linea 2 relativa ai C Lab sud-isole - D.D. Miur n. 1513 del 15/06/2017- CUP di Progetto F82C17000610007.

The authors would like to thanks all the Italian Contamination Labs participating to this research.

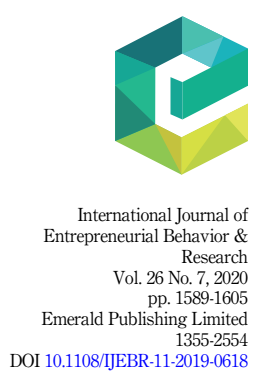


IJEBR

26,7
Originality/value - The originality of the work regards the contribution to the emerging role of digital technologies on the student's entrepreneurship.

Keywords Academic entrepreneurship, Entrepreneurship centres, Entrepreneurship education, Digital technologies, Digital transformation, Contamination labs

Paper type Research paper

\section{Introduction}

Extant research suggests that entrepreneurship centres (Cassia et al., 2014; Maas and Jones, 2017) can play an important role in stimulating entrepreneurship activities within higher education institutions (Finkle et al., 2006, 2013; Nelles and Vorley, 2011; Secundo et al., 2016). Their activity is especially relevant for increasing the visibility of entrepreneurship as a competence, a profession or as a field of study (Cassia et al., 2014; Fisher and Reuber, 2011). According to Siegel and Wright (2015), the establishment and growth of entrepreneurship centres are an emerging perspective framed within academic entrepreneurship that includes a wider social and economic benefit to the university ecosystem overcoming the traditional goal of economic revenue from research commercialization. The goals of entrepreneurship centres vary significantly between new firm creation, researching market opportunities, developing enterprising and entrepreneurship skills among students and staff and contributing to the capitalization of knowledge (Del-Palacio et al., 2008).

In recent years, the infusion of new digital technologies (such as social media, Internet of things, MOOCs, 3D printing, Big Data, etc.) that are reshaping society globally (Nambisan et al., 2017) has changed the nature of entrepreneurship and managerial challenges (Gawer and Cusumano, 2014) and has largely affected the activities of entrepreneurship research centres. Digital technologies are opening up fascinating innovation opportunities and can become the dominant source for innovation also in entrepreneurship centre (Cohen et al., 2017; Urbinati et al., 2017; Yoo, 2010). Even if different studies recall and demonstrate the importance of these digital technologies as strategic for spin-offs creation, for entrepreneurship education, for licensing and research development, to the best of our knowledge surprisingly few studies have focussed on the analysis of digital technologies in the whole spectrums of entrepreneurship centres activities and processes (Rippa and Secundo, 2018).

To cover this research gap, attention is focussed on a public initiative of the Italian Ministry of University and Research (MIUR) which in 2012 financed the creation of the Contamination Labs (CLabs), that is, virtual and physical environments where university students with different background could be involved into entrepreneurial learning activities, working on the incubation of their ideas and the development of a business plan. Within CLabs, university students are involved in typical activities of entrepreneurship education such as idea generation, creative thinking, business games, elevator pitch, business plan competitions or idea challenges proposed by companies. Huffman and Quigley (2002) and Russell et al. (2008) noted that business plan competitions provide a mechanism for new business start-up and for encouraging entrepreneurial ideas (Passaro et al., 2017), talents and potential entrepreneurs. Activities such as business skills development, team building, mentoring, judges' feedback and networking represent core activities of an effective business planning competition (Russell et al., 2008). Der Foo et al. (2005) noted their role in team building by utilizing new technologies. Streeter et al. (2002), and Atchison and Gotlieb (2004) identify that such competitions offer the opportunity to develop both generic skills and entrepreneurial mindset and business knowledge competencies.

The Italian experience of the CLabs provides a perfect setting for the analysis of how entrepreneurship research centres are adopting digital platforms to support a variety of entrepreneurial activities. According to the statements of the policymakers presenting the initiatives, CLabs were introduced as an initiative aiming at improving university students' 
entrepreneurial awareness and enterprising skills. In fact, unlike the traditional incubators and accelerators, the CLabs were intended to create a space for creative thinking and innovative project design, a "step back" primarily aimed to build a network that allows gathering the human capital needed for highly innovative projects (Boffo et al., 2015). From this perspective, CLabs are experimental learning projects for higher education institutions, aimed at facilitating the adoption of innovation into entrepreneurship research centres.

Aimed to provide evidence about the adoption and utilization of the digital technologies within the entrepreneurship education centres, this paper presents an in-depth analysis of 12 centres located in Italian universities findings offering some insights into the strategic role of some categories of digital technologies inside the CLabs. The main results show still a weak use of digital technologies in CLabs except for social media and digital platforms, mainly used for promotion scope and communication of the entrepreneurial outputs achieved by the students.

The remainder of the paper is organized as follows. Section 2 briefly introduces the background around the key concept of entrepreneurship centres and digital technologies. Section 3 introduces the research methodology. Section 4 presents the findings of our research. Section 5 proposes a discussion of the main findings, provides implications for theory and practices, describes limitations and future research and concludes the paper.

\section{Entrepreneurship education and digital technology}

The entrepreneurship education missions

Entrepreneurship education is the most relevant process that universities all around the world are activating through ad hoc entrepreneurial learning contents, approaches and processes to develop students' entrepreneurial awareness, attitudes and skills for contributing to the third mission achievement (Bae et al., 2014; Fayolle et al., 2006; Hahn et al., 2017). Several researchers have discussed the differences across countries and educational institutions in terms of objectives, target audiences, format and pedagogical approaches for developing an entrepreneurial mindset in university students (Fayolle and Klandt, 2006). However, if any differences exist, the similarities of the approaches to entrepreneurship education centre are more clearly identified in the general aim to foster the development of an entrepreneurial mindset in university students and in the involvement of a large community of stakeholders belonging to the local entrepreneurial ecosystem, which could contribute to deep contamination of knowledge, skills and experiences (Ndou et al., 2018).

As for the first point, the entrepreneurial mindset represents the competence of helping the members of society, students at all levels of education, young entrepreneurs and start-uppers to be creative and confident in whatever they undertake to cope with business uncertainty, ambiguity and complexity (Schaltegger and Wagner, 2011). Students at all levels of education, young entrepreneurs and start-uppers need to be equipped with an entrepreneurial mindset, which is defined by five constituent elements: (1) the capacity to think creatively, strategically, analytically and reflectively, (2) confidence in one's abilities, (3) the ability to collaborate, (4) well-developed communication skills and (5) an understanding of the current business context (Pollard and Wilson, 2014). As for the second point, that is, the stakeholders' involvement, universities should trigger collaborative links with a multiplicity of stakeholders including not only industry and other educational institutions but also the wider learning communities and regional entrepreneurs that belong to the wider university's entrepreneurial ecosystem (Redford and Fayolle, 2014).

\section{Transforming entrepreneurship education through digital technologies}

In parallel to the expansion and the strategic importance of entrepreneurship education, in the last ten years, the increasing use of advanced digital technologies is transforming innovation and production processes (Alcacer, Cantwell and Piscitello, 2016). The most important challenges, for entrepreneurship education, lie in the way of realizing the full potential of the
Entrepreneurship education centres 
IJEBR

26,7

emerging digital and smart technologies starting from a basic awareness about their potential role. In this context, digital and smart technologies have received greater attention in recent years in business and management practice, to offer products or services more competitive, sustainable and with optimized value for the involved stakeholders (Lombardi, 2019). The purpose of smart technologies is to create, deliver and manage intelligent products/services and/ or experiences, which is characterized by intensive information sharing for optimal and sustainable value creation or co-creation (Ardolino et al., 2018; Lenka et al., 2017; Wünderlich, et al., 2015).

Many classifications exist for digital technologies. Nambisan (2017) introduced the concept of digital technologies as a result of three distinct but related elements: digital artefacts, digital infrastructure and digital platforms. A digital artefact can be defined as a digital component, application or media content that is part of a new product (or service) and offers a specific functionality or value to the end user (Ekbia, 2009; Kallinikos et al., 2013). Digital infrastructure is defined as digital technology tools and systems that offer communication, collaboration and/ or computing capabilities (Nambisan, 2017). Infrastructure can be defined in general as the basic physical and organizational structures needed for the operation of a society or organizations (Tilson et al., 2010). Digital infrastructure as cloud computing, data analytics, online communities, social media, 3D printing, digital maker spaces can support the business process and the supply chain activities of companies. For example, 3D printing, also known as "additive manufacturing" or "rapid prototyping", is the printing of solid, physical 3D objects. Drawing on computer-aided design (CAD) files, 3D printing makes it possible to build physical models, prototypes, patterns, tooling components or production parts. Digital platforms are shared, a common set of services and architecture that serves to host complimentary offerings, including digital artefacts (Parker et al., 2016; Tiwana et al., 2010). Digital technologies as composed of digital artifacts, digital infrastructure and digital platforms could represent the basis of the digital transformation of entrepreneurial learning processes within universities and higher education institutions.

For this purpose, some experiences related to the utilization of digital technologies in the entrepreneurial university context can be reported. Gupta and Bharadwaj (2013) have developed a general framework for approaching entrepreneurship education in a business school through the use of augmented reality and social networks. Harte et al., (2012) proposed a toolkit based on the use of commercial software to increase attitudes towards entrepreneurship by STEM students. Developed at a Scottish university, EDGE (Encourage Dynamic and Global Entrepreneurs) uses social network technologies and electronic systems portfolios (Smith and Paton, 2010) for increasing the development of entrepreneurial competences. Birtchnell et al. (2017) converged to the idea that harnessing the existing activities in 3D printing and capitalizing on their existing regional presence as local providers of employment, investment and growth, universities stand to realize their third mission in a presently unforeseen way. The Invention Studio is a fab space created by Georgia Tech University where facilities, infrastructure and cultural transformation are demonstrating the value and sustainability of hands-on, design-build education to stimulate innovation, creativity and entrepreneurship in engineering undergraduates (Guerra Guerra and De Gomez, 2016). Finally, Al Atabi (2014) focusses on the achievement of university students in the acquisition of entrepreneurship competences through the massive open online course (MOOC) that allow collaborative learning of students as well as the acquisition of key entrepreneurial skills, such as opportunity identification in a digital learning environment.

\section{The Italian context and the creation of Contamination Labs}

The execution, implementation and practices of entrepreneurship education have been observed to vary across regions and institutions (Boffo et al., 2017). At the European level, the Entrepreneurship 2020 Action Plan (European Commission, 2013) stressed the challenge for 
nascent entrepreneurs in the context of the European economic downturn started in 2008, which severely affected the global and continental economy. In this direction, the European Union tried to face these structural changes through incentives for competitiveness and growth. Entrepreneurship represents one of the pillars of the Europe 2020 Strategy. An effective strategy for entrepreneurship "creates new companies and jobs, opens up new markets, and nurtures new skills and capabilities" (European Commission, 2013, p. 3). The implementation of national strategies for entrepreneurship leads to the development of supported programmes across the different member states.

An exemplary case is represented by Italy. The importance and the increasing relevance of the entrepreneurship education led to a significant increase in the supply of entrepreneurship courses in Italian universities over the past decade (Curci and Micozzi, 2017; Iacobucci and Micozzi, 2012). This trend has been largely supported by the MIUR through the creation and financing of the Italian CLabs, that is, physical environments where students are involved in the development of an entrepreneurial mindset, creativity and innovation through the adoption of learning strategies typical of the entrepreneurship education. The laboratory involves all the university students with different backgrounds (business, humanities, social science, science, engineering, biology, arts, etc.) through innovative extra-curricular activities within a learning programme having a during of six months. The MIUR started funding the CLabs through a first competitive call in 2012. The second round of funding has been provided in 2016 when a total of 16 CLabs projects have been financed in 16 public universities located in North, Centre and South Italy. All the CLabs have the same mission and vision. Furthermore, another common trait is represented by the adoption of hands-on practical experiential projects to help students in identifying more opportunities for defining knowledge-intensive ideas and launching new start-ups (e.g. Honig, 2004; DeTienne and Chandler, 2004).

While the strategic impact and role of digital technologies have been studied and analysed in extant literature (Bharadwaj et al., 2013; Giones and Brem, 2017; Mamaghani, 2016; Mihardjo et al., 2019; Pagani and Pardo, 2017), there is limited understanding of their potentialities for the entrepreneurship education centres: how these centres embrace these technological innovations remains largely unexplored. This gap assumes a strategic relevance in the Italian Contamination Labs where the entrepreneurial learning approaches are activated to realize technology-intensive projects, business ideas and solutions designed and implemented by the university students.

\section{Research methodology}

A qualitative approach based on multiple case study design to explore the aforementioned gap is adopted, because "a how or why the question is being asked about a contemporary set of events over which the investigator has little or no control” (Yin, 2009). Qualitative methods allow researchers to discover to reveal and understand relationships between variables even within complex processes and to illustrate the influence of the social context (Shah and Corley, 2006).

For our purpose, a multiple case study is a valid approach since a comparison of cases' findings by replication is required to the extent of the validity of results. As stated in Eisenhardt and Graebner (2007), multiple case studies offer the opportunity to collect more information available for theory building.

Our research investigates how much the Italian CLabs are adopting digital technologies to support the digital transformation of their entrepreneurship education activities for university students. About 12 case studies, extracted from the list of 17 Italian CLabs, are actually fully committed towards their activities. The multiple case study approach will provide interesting results about the actual and future revolution of digital technology that could allow within the CLabs to sustain their entrepreneurial education processes.

Entrepreneurship education centres 
IJEBR

26,7

1594

\section{Research context}

The basic values of the CLabs are interdisciplinarity and contamination among different experiences, backgrounds and competences through the development of novel business ideas and innovation projects in close collaboration with the entrepreneurial ecosystem.

The Italian Programme for Research foresees a strengthening of the investment in the CLabs, intended as virtual and physical places of contamination between university students and graduate students of different disciplines. In 2016, 17 CLabs had been launched by 17 Italian universities starting from a competitive call at the national level involving all the universities. Among those CLabs, at the time of the survey, 12 were operative and they had already started the educational activities. So far, our analysis will comprise the whole set of the active CLabs in Italy. The main idea behind the CLab is to create a place where: (1) it is possible to foster cooperation among students, entrepreneurs and academics; (2) students, entrepreneurs and academics share knowledge and create new understandings and work together to form plans of action (co-learning); (3) students set their agendas and then act with the help of entrepreneurs and academics; (4) students are embedded into the entrepreneurial culture; (5) teachers and mentors show the best practice in entrepreneurship and innovation in the creation of new businesses; and (6) students learn to manage all stages of the knowledge transfer process to support organic growth within the high technology sector for setting up a start-up.

CLab's entrepreneurial learning activities are part of the students' curriculum as an optional course, specifically, attendance of structured seminars, business competition and all the learning activities organized within the CLab can be worthy as ECTS (European Credit Transfer and Accumulation System). The scientific committee of each CLab decides the criteria for evaluating the admission of students within the extra-curricular programme, considering not only the knowledge acquired but also the student's attitude for working as a team, their motivations to participate in this innovative programme and the business idea they would like to develop. Each CLab has received financial resources to activate programmes and activities devoted to students for three years. So generally, all the CLabs started their first edition programme in the first year of funding (2017) and will continue the organization of programmes till the third year (2020). The characteristics of the programmes, the number of students involved, the entrepreneurship contents and learning approaches can differ from one university to another, according to their previous experience and the presence of a technology transfer office. The Italian CLab Network is the network connecting all the CLabs, and it is managed by the University of Cagliari Contamination Lab (http://clabitalia.it/).

\section{Data collection and analysis}

Improving transparency is useful for readers to describe what was done within case studies and to guide other researchers who wish to conduct similar research (Massaro et al., 2019a, b). About 12 Italian CLabs have been analysed. All the CLab chiefs (coordinators) in the list were firstly contacted by e-mail and with positive respondents, a skype call was agreed to collect further details about their mission, process and activities. Moreover, a web survey has been prepared to address the main questions related to the types and intensity of adoption of digital technologies. The survey is divided into three sections. The first is a general section, where a question about the governance structure of the CLabs is formulated (university of affiliation, number of employees, types of managerial structure, typologies of activities performed). In the second section, respondents are required to indicate the types of digital technologies adopted and the related impact and also which technologies will be strategically adopted in the future. Digital technologies had been listed based on the authors' elaboration of the digital artefact, platform and infrastructure concepts by Nambisan (2017). A final section asks respondents to indicate barriers and constraints to the adoption of digital technologies in their daily activities. 
According to Yin (2009), the construct validity of case studies is increased through multiple sources of evidence and key informant interviews. Phone or face-to-face interview was agreed in the period January 2019-April 2019 to finalize the data analysis. First of all, the project manager of one of the 17 Italian CLabs has been involved in this research (see Figure 1). Indeed, the questionnaire has been prepared and validated in collaboration with two experts. The first one is the project manager of one CLab, while the second is the general manager of a university incubator (thus with very similar expertise). Additional documents such as internal reports and information extracted through the websites and Facebook pages were collected to check their consistency with the information acquired during the survey.

Entrepreneurship education centres

\section{Findings: CLabs'entrepreneurship activities}

Table 1 presents a description of the CLabs' sample. The CLab's list shows an equal distribution among North (4), Centre (2) and South (5) Italy. The total funded amount is $4.1 \mathrm{~m}$ Euros. The extra-curricular entrepreneurial programme of each CLabs is strictly guided by the MIUR according to the general recommendation of the European Union in terms of entrepreneurial competencies development (European Commission, 2013). In some cases, the duration of the entrepreneurship education programme is six months, in other cases three months; for this reason, big differences in terms of the number of trained students are reported in Table 1.

\section{CLab strategic entrepreneurship activities now and in the future}

Academic entrepreneurship requires specific activities to make the university more entrepreneurial. Among these, the entrepreneurship education centres can play a strategic role of intermediary between researchers and industries, providing facilities and opportunities to enhance the social and economic impact on the territory. Activities such as the creation of spin-offs and start-ups, the engagement of local communities through events and workshops, entrepreneurial education activities, the organizations of business plan competitions and finally, contracts with industries and public administrations can be identified (Siegel and Wright, 2015).

Each CLab was asked which of those activities are considered as the most strategic in the present and which they supposed to be strategic in the immediate future. The questionnaire is a five-point Likert scale, with 5 representing extremely strategic" and 1 "poorly strategic". The questions were intended to observe the level of importance in the present situation and after three years. Data are presented in an aggregated way, and Figure 2 reports the average of each activity as reported by every CLab.

\begin{tabular}{|c|c|c|c|c|c|}
\hline CLAB id & Macro-region & First year & \# Editions & \# Students & \\
\hline CLab 1 & South & 2017 & 2 & 120 & \\
\hline CLab 2 & North & 2017 & 2 & 130 & \\
\hline CLab 3 & South & 2014 & 5 & 500 & \\
\hline CLab 4 & South & 2017 & 2 & 90 & \\
\hline CLab 5 & Centre & 2013 & 6 & 536 & \\
\hline CLab 6 & South & 2014 & 16 & 640 & \\
\hline CLab 7 & Centre & 2013 & 5 & 60 & \\
\hline CLab 8 & South & 2017 & 3 & 120 & \\
\hline CLab 9 & North & 2017 & 2 & 200 & Table 1. \\
\hline CLab 10 & North & 2013 & 6 & 580 & Contamination Labs in \\
\hline CLab 11 & North & 2018 & 2 & 60 & Italy (data updated in \\
\hline CLab 12 & North & 2017 & 2 & 80 & November 2019) \\
\hline
\end{tabular}




\section{IJEBR \\ 26,7}

1596

Figure 1.

The Italian Network of

Contamination Lab financed by MIUR in 2016 (Own elaboration)

Figure 2.

\section{CLabs'}

entrepreneurship education activities' importance in the present (now) and in the future (in three years)
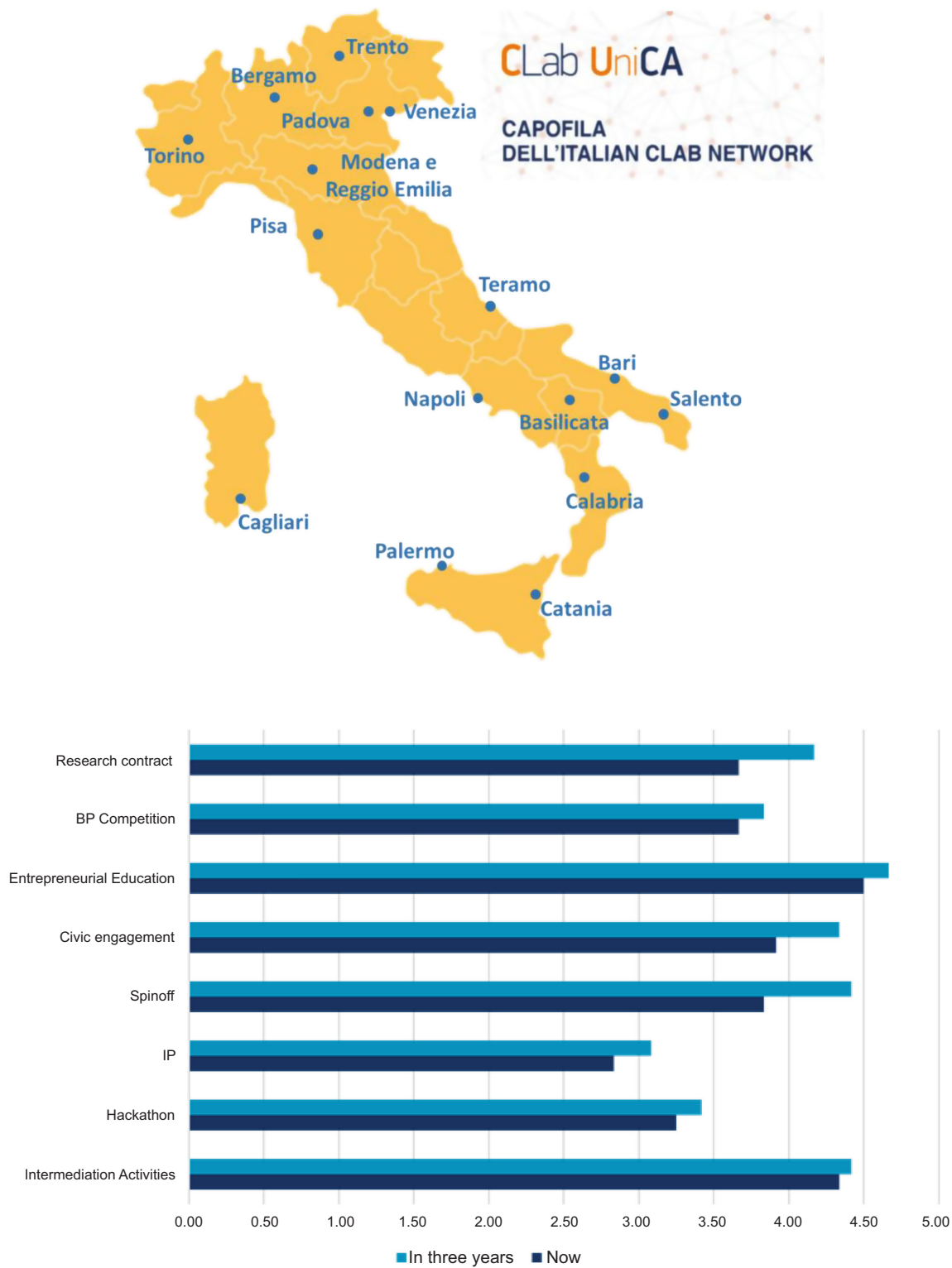

Right now, the most strategic activity expressed by CLabs is entrepreneurship education with an average score of 4.50 followed by intermediation activities (with 4.33). On the contrary, the less strategic initiatives promoted by the CLabs are the management of intellectual property rights and hackathons. This is in line with the general aim and mission of the CLab.

When looking at the prospective strategic activities CLabs aim to plan, the most relevant one remains entrepreneurship education (with 4.67). This is reasonable as literature 
demonstrated how education is the most powerful tool to train young people and to guide them in the achievement at first of an entrepreneurial mindset and awareness. Looking at the deltas between the present and future strategic activities, research contracts with external actors and start-up/spin-off creation are the two activities that count the largest difference. This means that CLabs are considering strengthening those two areas of activities. This result is coherent with the fact that the CLabs are financed just for three years by the MIUR and that they are looking for becoming sustainable in the long period to become permanent research centres for entrepreneurship to accomplish the third mission aim.

Entrepreneurship education centres

\section{Adoption of digital technologies within the Italian CLabs}

Digital technologies can be adopted by CLabs to support entrepreneurial activities involving the university students. blockchain, virtual and augmented reality, 3D labs, digital platforms are nowadays used to increase the entrepreneurial behaviour of students. CLabs were surveyed to indicate which technologies are currently used and which digital technologies CLabs forecast to adopt in the next future. Ten different categories of digital technologies were listed, asking managers of CLabs to indicate, using a five-point Likert scale, the degree of adoption of every single technology in their daily activities. An aggregate value was reported, as the average of the CLabs answers.

Social media is the most adopted technologies, with an average score of 4.33. The digital platform, with 3.17, is the second most used digital technology. In general, CLabs make still little use of digital technologies for their daily activities. Digital technologies are mainly used for the promotional purpose (see Figure 3).

When analysing the future strategies of digital technologies adoption for the digital transformation of their entrepreneurship education processes, there is a consensus about the intention to adopt distance learning technologies to improve students' participation in the general seminars focussed on the acquisition of knowledge about the global future trends, business management and business planning. MOOC, indeed, is the technology with the highest delta when comparing actual and future declaration of digital technologies adoption. This means that in the future some of the learning processes of the CLab could also integrate the physical and the digital environment for increasing the student's motivation and participation in all the scheduled initiatives.

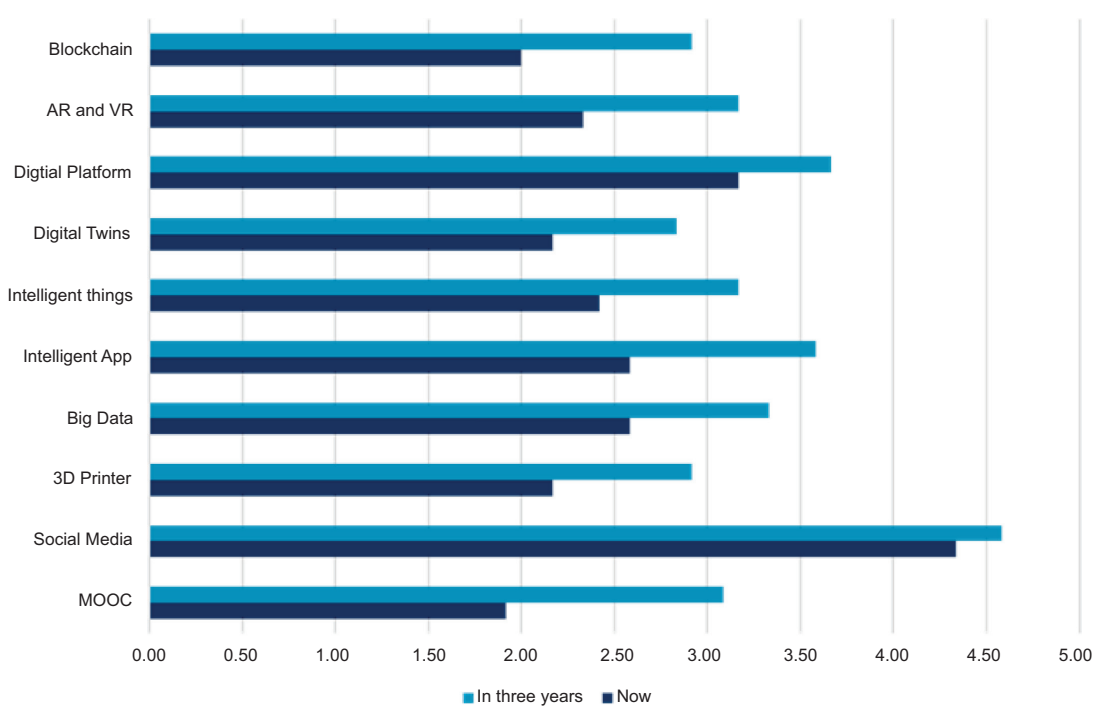

Figure 3. Adoption of digital technologies within the Italian CLabs 
IJEBR

26,7

\section{8}

Figure 4.

Impact of digital technologies on activities carried out by the CLabs
This evidence could be explained by the fact that in this first phase of activities, CLabs are more focussed on the development and management of the entrepreneurial learning activities to facilitate the generation of students' business ideas.

\section{Impact of digital technologies adoption in the CLabs}

Furthermore, the analysis focusses on the level of impact of each digital technology family on the activities organized and managed by the CLabs (Figure 4). Three digital technology families were classified, to make the survey easier to be filled by the interviewed CLab chief and/or CLab project managers. Technologies were classified in the following groups: technologies such as social media and MOOC in DI (digital infrastructure); technologies such as IoT, 3D printer, Big Data, Intelligent app in DP (digital platform); and finally, technologies such as augmented and virtual reality, blockchain in DA (digital artefact). In the questionnaire, it was asked to indicate the impact of the digital technology families on the activities based on a four-point scale: no impact at all (0), low impact (1), medium impact (2), high impact (3). In general, the impact appears to be low or with no impact at all. Few CLabs adopt strategically some digital technologies while some CLabs do not use at all any digital technologies or they do not rely on any impact on their entrepreneurship activities. DIs present the highest rate of impact, especially on intermediation activities, spin-off and start-up activities, local community engagement activities, entrepreneurial education activities and business plan competition activities. This is probably because social media is a technology included in this family, and as previously shown, social media is the most used technology by CLabs.

What are the strategic activities carried on by the CLabs and the digital technologies adopted to facilitate such activities? The picture that emerged from this section reports a medium capacity of the CLabs to strategically involve external actors in their activities and a medium ability to promote new venture creations among their students. Moreover, as a sort of validation of the previous analysis, managers of CLabs declare a medium use of digital technologies to engage and inspire new entrepreneurs as a result of their activities.

\section{Entrepreneurial strategic activities and barriers to the adoption of digital technologies}

The final section of the survey regards the ability of the CLabs to involve students and researchers in entrepreneurial activities such as the creation of new firms and to take

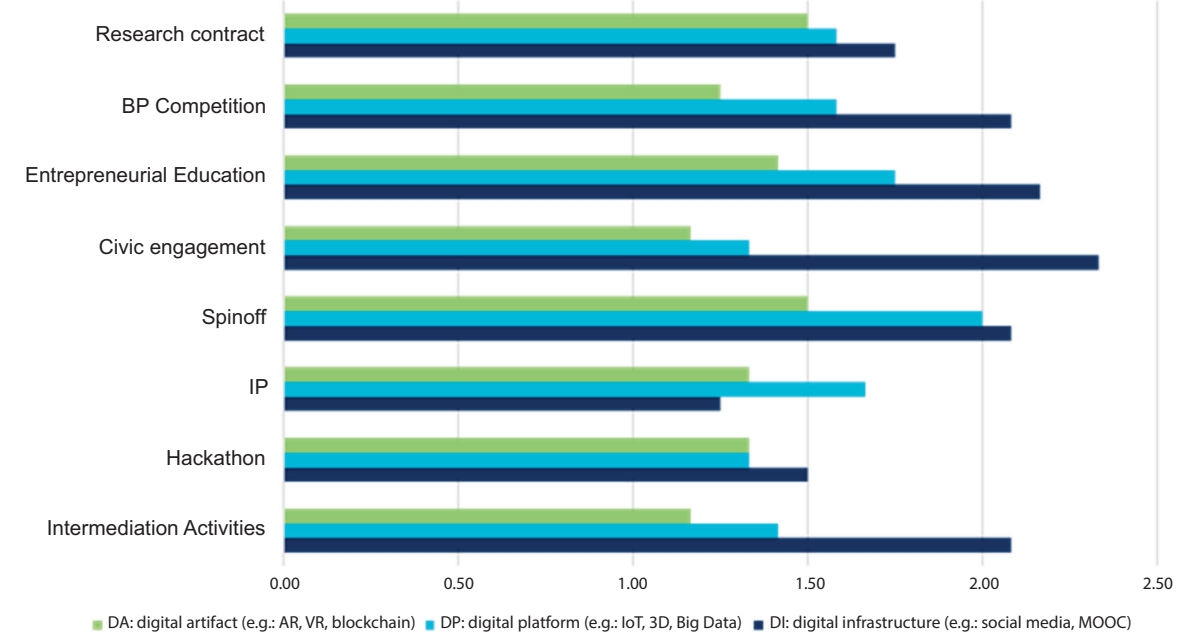


advantage of the internal activities to establish fruitful collaborations with external partners, firms and institutions.

The questionnaire asks managers of the CLabs how much they are under the following question:

(1) Ability to involve researchers and technicians in new venture creation activities;

(2) Ability to promote new venture creation by the students;

(3) Ability to retain ex-students;

(4) Ability to engage citizens and external actors;

(5) Ability to collaborate with firms and institutions;

(6) Ability to create strategical collaborations with firms.

Figure 5 represents the aggregate level of accordance with each question. The strategical collaboration with firms is the most rated interest expressed by the CLabs. The "new venture creations" from students, as well as from researchers and technicians, have been the most important promoted activities.

When looking into the main barriers and constraints to the adoption of digital technologies, it appears that the most critical one is cultural. Digital technologies are not so much diffused regularly in the daily activities of the university they belong to. And this aspect creates high constraints for the adoption of technologies to support students in their entrepreneurial activities. Costs of the adoption of digital technologies is a matter, but it does not represent the main obstacles. Also, the most cited criticalities to solve their missions and scopes are difficulties when involving internal professors and technicians in the CLabs activities and the great heterogeneity of the class appears to be a limit when evaluating the general involvement of the students. Cultural constraint means a low level of commitment from the adopters' side and a low level of time to be dedicated to the initiative of selection, adoption and utilization of digital technologies.

\section{Discussion and conclusion}

This paper analysed whether the entrepreneurship education centres introduced by the Italian Ministry of Higher Education and Research in 2012 (the Italian Contamination Labs -
Entrepreneurship education centres

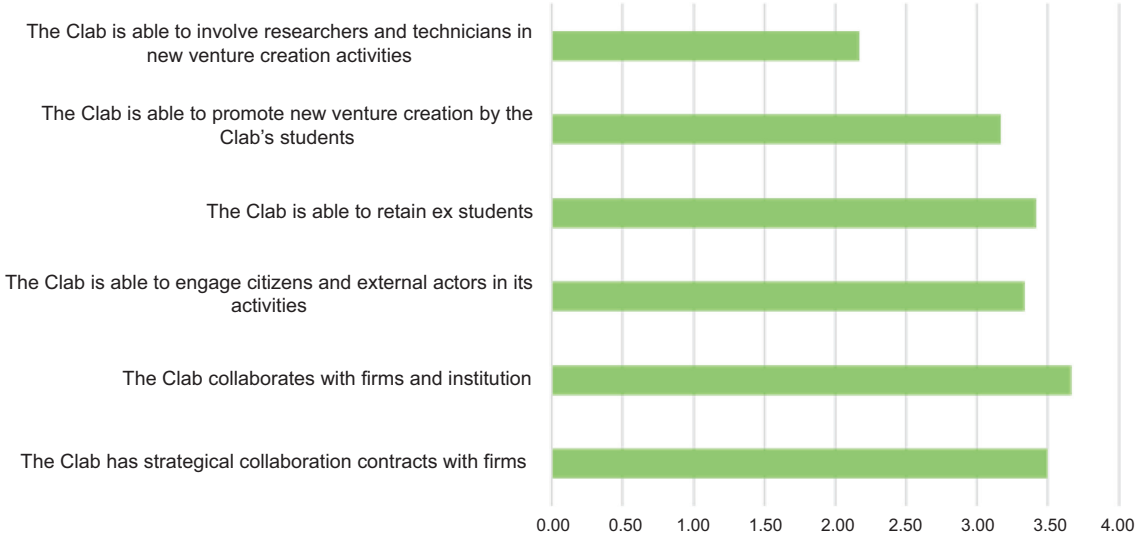

Figure 5.

Strategic activities of stakeholders' involvement within the CLabs 
IJEBR

26,7

CLabs) are effectively adopting the emergent digital technologies for nurturing their entrepreneurship education activities and dissemination of knowledge contamination practices among university students.

An in-depth analysis of 12 Italian CLabs provided evidence about the direct role played by digital technologies in supporting and enhancing the entrepreneurial processes, as well as on their indirect role in stimulating entrepreneurship activities of nascent student entrepreneurs. The empirical analysis provides evidence about the possibilities and constraints of digital technologies for goals, governance and processes of entrepreneurship centres, enabling a better understanding of the challenges posed by the ongoing digital transformation. In particular, CLabs responding to our survey manifested a low level of adoption of digital technologies. On the one hand, social media such as Facebook are widely adopted, though their use is limited to the promotion of CLab activities. This evidence allows the identification of room for improvement, as extant literature demonstrates how social media can transform how people and organizations relate. Government organizations are experimenting with social media to communicate with their constituents, and many analysts see in these media a powerful set of tools to reinvent government-citizen relationships (Picazo-Vela et al., 2012).

Technologies such as blockchain, big data, 3D printers are poorly adopted. Surprisingly, $\mathrm{MOOC}$ is not adopted nor considered as strategic. This evidence provides another room for improvement, given that extant literature suggests that the MOOC is a suitable platform to teach entrepreneurship as it provides tools to enable students collaborative learning as well as improve individuals affective key entrepreneurial aspects such as opportunity recognition and resource acquisition (Al-Atabi and De Boer, 2014). Indeed, MOOCs could allow many participants to enrol in entrepreneurship education (Romero, 2013) so contributing to the diffusion of wide entrepreneurial culture and mindset among the university students.

The strategic vision for the future changes a little bit since such digital technologies are viewed as important for the sustainability of the entrepreneurship centre, but cultural and time constraints are highlighted as the most important barriers to the adoption of the digital technologies, confirming the difficulties in the digital transformation of the entrepreneurship education already identified in other fields (Bacow et al., 2012; Watty et al., 2016). There is the need to know more about what entrepreneurship or enterprise education actually "is" when implemented in practice, and the real challenge could be to embed this type of course in the universities' curriculum as a compulsory course (Volkmann and Audretsch, 2017). This is problematic because the entrepreneurial strategy for teaching entrepreneurship is the antithesis of traditional approaches to teaching. Academic assessment processes evaluate and test knowledge and skill rather than behaviour and skills, therefore widening the assessment process to accommodate behaviour is the real challenge for academic institutions, although it is a challenge that is beginning to be undertaken. Academic policy and decision-makers need to be convinced of the value in offering such entrepreneurship courses before they can be included in mainstream programmes. Arguably the faculty for such typology, of course, needs to be composed not only by university professors but especially by managers and entrepreneurs that can diffuse their entrepreneurial behaviours to establish such programmes in mainstream academia.

\section{Implications for theory}

Research implications regard the potential role that digital technologies could play in supporting and enhancing the processes that the Italian CLabs could play (e.g. presenting their programmes and activities) and their indirect role (e.g. undertake joint programmes/ activities with other faculties) in promoting enterprise and entrepreneurship activities of the 
academic entrepreneurs. The CLabs are born as centres for the development of the entrepreneurial mindset in university students through a virtuous knowledge and experience contamination process within the local entrepreneurial ecosystem. This aim is achieved through the creation of entrepreneurial learning environments that can facilitate the sharing of experiences coming from different disciplinary fields, both in students and in faculty. This approach is in line with some empirical evidence that the literature illustrates as successful cases of development paths of entrepreneurial processes (Russell et al., 2008). The Italian experience can be considered of sure success, but to fully understand the degree of effectiveness of these entrepreneurship centres, the present study tried to investigate the degree of diffusion of digital technologies in support of their entrepreneurial activities and processes. The conviction of the authors lies in the awareness of the power of the new digital technologies to accelerate not only the production processes in business but also the educational ones and in particular, those of entrepreneurship education. The use of technologies such as e-learning, additive manufacturing, augmented reality can favour the creation of environments able to accelerate the learning processes of the development of new enterprises launched by students.

In the context of entrepreneurship education, such as that of the CLabs, the adoption of digital platforms, digital infrastructures and digital artefacts can support the operational methods of knowledge creation, knowledge sharing among students with different backgrounds, development of entrepreneurial skills (Gawer and Cusumano, 2014; Yoo, 2010; Urbinati et al., 2017).

\section{Implications for practice}

From the results obtained it is not possible to develop a replicable recipe in different contexts. However, some possible strategies for adopting digital technologies emerge which, by transforming the development processes of innovations (Alcacer et al., 2016), can stimulate new ideas and facilitate the start-up of new businesses. Furthermore, the massive use of digital and smart technologies also enables the development of more competitive, sustainable products and services capable of involving a wider network of stakeholders (Lombardi, 2019). In line with the digital academic entrepreneurship framework (Rippa and Secundo, 2018), new ways of managing entrepreneurship centres (such as) are being developed, which thanks to the use of new technologies can involve a network of subjects broader (who) and with aims and mission more focussed on sustainability and competitiveness of results (what). Furthermore, practical implications concern insights for the entrepreneurship centre governance body involved in the guidance of processes such as entrepreneurial competence development, knowledge transfer and innovation in the university ecosystem and social engagement through the utilization of digital technologies.

\section{Limitations of the study and future research}

The main limitation regards the fact that the study has been realized just at the beginning of the first year of entrepreneurship education activities for each CLab. A new survey will be launched at the end of the third year when each CLab formally will close the current activities financed by the MIUR. This will allow us to compare the results and identify trends of the digital transformation within the Italian entrepreneurship education centres.

\section{References}

Al-Atabi, M. and DeBoer, J. (2014), "Teaching entrepreneurship using massive open online courses (MOOC)", Technovation, Vol. 34 No. 4, pp. 261-264. 
IJEBR

26,7

1602

Alcácer, J., Cantwell, J. and Piscitello, L. (2016), "Internationalization in the information age: a new era for places, firms, and international business networks?", Journal of International Business Studies, Vol. 47 No. 5, pp. 499-512.

Ardolino, M., Rapaccini, M., Saccani, N., Gaiardelli, P., Crespi, G. and Ruggeri, C. (2018), "The role of digital technologies for the service transformation of industrial companies", International Journal of Production Research, Vol. 56 No. 6, pp. 2116-2132.

Atchison, M. and Gotlieb, P. (2004), "Innovation and the future of cooperative education", in Coll, R. and Eames, C. (Eds), International Handbook for Cooperative Education: An International Perspective of the Theory, Research, and Practice of Work-Integrated Learning, World Association for Cooperative Education, Boston, MA, pp. 261-9.

Bacow, L.S., Bowen, W.G., Guthrie, K.M., Long, M.P. and Lack, K.A. (2012), Barriers to Adoption of Online Learning Systems in US Higher Education, Ithaka, New York, NY, pp. 39-51.

Bae, T.J., Qian, S., Miao, C. and Fiet, J.O. (2014), "The relationship between entrepreneurship education and entrepreneurial intentions: a meta-analytic review", Entrepreneurship: Theory and Practice, Vol. 38 No. 2, pp. 217-254.

Bharadwaj, A., El Sawy, O.A., Pavlou, P.A. and Venkatraman, N. (2013), "Digital business strategy: toward a next generation of insights", MIS Quarterly, Vol. 37 No. 2, pp. 471-482.

Birtchnell, T., Böhme, T. and Gorkin, R. (2017), "3D printing and the third mission: the university in the materialization of intellectual capital", Technological Forecasting and Social Change, Vol. 123, pp. 240249.

Boffo, V., Adebakin, A.B. and Terzaroli, C. (2017), "Supporting entrepreneurship in higher education for young adults' employability: a cross-border comparative study", Adult Education and Work Contexts: International Perspectives and Challenges, pp. 123-142.

Boffo, V., Federighi, P. and Torlone, F. (2015), Educational Jobs: Youth and Employability in the Social Economy: Investigations in Italy, Malta, Portugal, Romania, Spain, United Kingdom, Firenze University Press, Firenze, Vol. 2.

Cassia, L., De Massis, A., Meoli, M. and Minola, T. (2014), "Entrepreneurship research centers around the world: research orientation, knowledge transfer and performance", Journal of Technology Transfer, Vol. 39 No. 3, pp. 376-392.

Cohen, B., Amorós, J.E. and Lundyd, L. (2017), "The generative potential of emerging technology to support startups and new ecosystems", Business Horizons, Vol. 60 No. 6, pp. 741-745.

Curci, N. and Micozzi, A. (2017), "Entrepreneurial activity and education in Italy", L'industria, Vol. 38 No. 3, pp. 385-410.

Del-Palacio, I., Sole, F. and Batista-Foguet, J.M. (2008), "University entrepreneurship centres as service businesses”, The Service Industries Journal, Vol. 28 No. 7, pp. 939-951.

Der Foo, M., Wong, P.K. and Ong, A. (2005), "Do others think you have a viable business idea? Team diversity and judges' evaluation of ideas in a business plan competition", Journal of Business Venturing, Vol. 20 No. 3, pp. 385-402.

DeTienne, D.R. and Chandler, G.N. (2004), "Opportunity identification and its role in the entrepreneurial classroom: a pedagogical approach and empirical test", The Academy of Management Learning and Education, Vol. 3 No. 3, pp. 242-257.

Eisenhardt, K.M. and Graebner, M.E. (2007), "Theory building from cases: opportunities and challenges”, Academy of Management Journal, Vol. 50 No. 1, pp. 25-32.

Ekbia, H.R. (2009), "Digital artifacts as quasi-objects: qualification, mediation, and materiality", Journal of the American Society for Information Science and Technology, Vol. 60 No. 12, pp. 2554-2566.

European Commission (2013), Entrepreneurship 2020. Action Plan Reigniting the Entrepreneurial Spirit in Europe. Communication from the Commission to the European Parliament, the Council, the European Economic and Social Committee and the Committee of the Regions, COM, European Commission, available at: https://goo.gl/WCmgGo. 
Fayolle, A. and Klandt, H. (Eds). (2006), International Entrepreneurship Education: Issues and Newness, Edward Elgar Publishing, Cheltenham.

Fayolle, A., Gailly, B. and Lassas-Clerc, N. (2006), "Assessing the impact of entrepreneurship education programmes: a new methodology", Journal of European Industrial Training, Vol. 30 No. 9, pp. 701-720.

Finkle, T.A., Kuratko, D.F. and Goldsby, M.G. (2006), "An examination of entrepreneurship centers in the United States: a national survey", Journal of Small Business Management, Vol. 44 No. 2, pp. 184-206.

Finkle, T.A., Menzies, T.V., Kuratko, D.F. and Goldsby, M.G. (2013), "An examination of the financial challenges of entrepreneurship centers throughout the world", Journal of Small Business and Entrepreneurship, Vol. 26 No. 1, pp. 67-85.

Fischer, E. and Reuber, A.R. (2011), "Social interaction via new social media: (how) can interactions on Twitter affect effectual thinking and behavior?", Journal of Business Venture, Vol. 26 No. 1, pp. 1-18.

Gawer, A. and Cusumano, M.A. (2014), "Industry platforms and ecosystem innovation”, Journal of Product Innovation Management, Vol. 31 No. 3, pp. 417-433.

Giones, F. and Brem, A. (2017), "Digital technology entrepreneurship: a definition and research agenda", Technology Innovation Management Review, Vol. 7 No. 5, pp. 44-51.

Guerra Guerra, A. and De G mez, L.S., (2016), "From a FabLab towards a social entrepreneurship and business lab", Journal of Cases on Information Technology, Vol. 18 No. 4, pp. 1-21.

Gupta, N. and Bharadwaj, S.S. (2013), "Agility in business school education through richness and reach: a conceptual model”, Education and Training, Vol. 55 No. 4, pp. 370-384.

Hahn, D., Minola, T., Van Gils, A. and Huybrechts, J. (2017), "Entrepreneurial education and learning at universities: exploring multilevel contingencies", Entrepreneurship and Regional Development, Vol. 29 Nos 9-10, pp. 945-974.

Harte, V., Stewart, J., Watts, C.A. and Wray, K. (2012), "Using toolkits to achieve STEM enterprise learning outcomes", Education+ Training.

Honig, B. (2004), "Entrepreneurship education: toward a model of contingency-based business planning", The Academy of Management Learning and Education, Vol. 3 No. 3, pp. 258-273.

Huffman, D. and Quigley, J.M. (2002), "The role of university in attracting high tech entrepreneurship: a Silicon Valley tale", The Annals of Regional Science, Vol. 36 No. 3, pp. 403-19.

Iacobucci, D. and Micozzi, A. (2012), "Entrepreneurship education in Italian universities: trend, situation and opportunities", Education + Training, Vol. 54 Nos 8/9, pp. 673-696.

Kallinikos, J., Aaltonen, A. and Marton, A. (2013), "The ambivalent ontology of digital artifacts”, MIS Quarterly, pp. 357-370.

Lenka, S., Parida, V. and Wincent, J. (2017), "Digitalization capabilities as enablers of value co-creation in servitizing firms", Psychology and Marketing, Vol. 34 No. 1, pp. 92-100.

Lombardi, R. (2019), "Knowledge transfer and organizational performance and business process: past, present and future researches”, Business Process Management Journal, Vol. 25 No. 1, pp. 2-9.

Maas, G. and Jones, P. (2017), Entrepreneurship Centres: Global Perspectives on Their Contributions to Higher Education Institutions, Palgrave Macmillan, London, pp. 11-16.

Mamaghani, F. (2016), "Strategic impact of big data on competitiveness", International Journal of Strategic Management, Vol. 16 No. 1, p. 21.

Massaro, M., Moro, A., Aschauer, E. and Fink, M. (2019a), "Trust, control and knowledge transfer in small business networks", Review of Managerial Science, Vol. 13 No. 2, pp. 267-301.

Massaro, M., Dumay, J. and Bagnoli, C. (2019b), "Transparency and the rhetorical use of citations to Robert Yin in case study research", Meditari Accountancy Research, Vol. 27 No. 1, pp. 44-71.
Entrepreneurship education centres 
IJEBR

26,7

1604

Mihardjo, L.W.W., Sasmoko, Alamsjah, F. and Elidjen. (2019), "Digital transformation: a transformational performance-based conceptual model through co-creation strategy and business model innovation in the Industry 4.0 in Indonesia", International Journal of Economics and Business Research, Vol. 18 No. 3, pp. 369-386.

Nambisan, S. (2017), "Digital entrepreneurship: toward a digital technology perspective of entrepreneurship", Entrepreneurship: Theory and Practice, Vol. 41 No. 6, pp. 1029-1055.

Nambisan, S., Lyytinen, K., Majchrzak, A. and Song, M. (2017), "Digital innovation management: reinventing innovation management research in a digital world", MIS Quarterly, Vol. 41 No. 1, pp. 223-238.

Ndou, V., /, G., Schiuma, G. and Passiante, G. (2018), "Insights for shaping entrepreneurship education: evidence from the European entrepreneurship centers", Sustainability, Vol. 10 No. 11, p. 4323.

Nelles, J. and Vorley, T. (2011), "Entrepreneurial architecture: a blueprint for entrepreneurial universities", Canadian Journal of Administrative Sciences, Vol. 28 No. 3, pp. 341-353.

Pagani, M. and Pardo, C. (2017), "The impact of digital technology on relationships in a business network", Industrial Marketing Management, Vol. 67, pp. 185-192.

Parker, G.G., Van Alstyne, M.W. and Choudary, S.P. (2016), Platform Revolution: How Networked Markets Are Transforming the Economy and How to Make Them Work for You, WW Norton and Company, New York, NY.

Passaro, R., Quinto, I. and Thomas, A. (2017), "Start-up competitions as learning environment to foster the entrepreneurial process", International Journal of Entrepreneurial Behaviour and Research, Vol. 23 No. 3, pp. 426-445.

Picazo-Vela, S., Gutiérrez-Martínez, I. and Luna-Reyes, L.F. (2012), "Understanding risks, benefits, and strategic alternatives of social media applications in the public sector", Government Information Quarterly, Vol. 29 No. 4, pp. 504-511.

Pollard, V. and Wilson, E. (2014), "The 'entrepreneurial mindset' in creative and performing arts higher education in Australia", Artivate, Vol. 3, pp. 3-22.

Redford, D.T. and Fayolle, A. (2014), Hanbook on the Entrepreneurial University, Cheltenham, Edward Elgar Publishing.

Rippa, P. and Secundo, G. (2018), "Digital academic entrepreneurship: the potential of digital technologies on academic entrepreneurship", Technological Forecasting and Social Change, pp. 900-911, doi: 10.1016/j.techfore.2018.07.013.

Romero, M. (2013), “Game based learning MOOC. Promoting entrepreneurship education”, Elearning Papers, Special Edition MOOCs and Beyond, Vol. 33, pp. 1-5.

Russell, R., Atchison, M. and Brooks, R. (2008), "Business plan competitions in tertiary institutions: encouraging entrepreneurship education", Journal of Higher Education Policy and Management, Vol. 30 No. 2, pp. 123-38.

Schaltegger, S. and Wagner, M. (2011), "Sustainable entrepreneurship and sustainability innovation: categories and interactions", Business Strategy Environment, Vol. 20, pp. 222-237.

Secundo, G., Ndou, V. and Del Vecchio, P. (2016), "Challenges for instilling entrepreneurial mindset in scientists and engineers: what works in European universities?", International Journal of Innovation and Technology Management, Vol. 13 No. 05, p. 1640012.

Shah, S.K. and Corley, K.G. (2006), "Building better theory by bridging the quantitative-qualitative divide", Journal of Management Studies, Vol. 43 No. 8, pp. 1821-1835.

Siegel, D.S. and Wright, M. (2015), “Academic entrepreneurship: time for a rethink?”, British Journal of Management, Vol. 26 No. 4, pp. 582-595.

Smith, A. and Paton, R.A. (2010), "An entrepreneurship toolkit for intensive skills development", International Journal of Entrepreneurship and Small Business, Vol. 9 No. 2, pp. 162-176. 
Streeter, D.H., Jaquette, J.P. and Hovis, K. (2002), University-wide Entrepreneurship Education: Alternative Models and Current Trends, Department of Applied Economics and Management and Cornell University, Ithaca, NY.

Tilson, D., Lyytinen, K. and Sørensen, C. (2010), "Research commentary-digital infrastructures: the missing IS research agenda”, Information Systems Research, Vol. 21 No. 4, pp. 748-759.

Tiwana, A., Konsynski, B. and Bush, A.A. (2010), "Research commentary-platform evolution: coevolution of platform architecture, governance, and environmental dynamics", Information Systems Research, Vol. 21 No. 4, pp. 675-687.

Urbinati, A., Chiaroni, D., Chiesa, V. and Frattini, F. (2017), "The role of digital technologies in the innovation process", in 24th Innovation and Product Development Management Conference, pp. 1-10.

Volkmann, C. and Audretsch, D. (2017), Entrepreneurship Education at Universities, Springer.

Watty, K., McKay, J. and Ngo, L. (2016), "Innovators or inhibitors? Accounting faculty resistance to new educational technologies in higher education", Journal of Accounting Education, Vol. 36, pp. 1-15.

Wünderlich, N.V., Heinonen, K., Ostrom, A.L., Patricio, L., Sousa, R. and Voss, C., et al. (2015), "'Futurizing" smart service: implications for service researchers and managers", Journal of Services Marketing, Vol. 29 Nos 6/7, pp. 442-447.

Yin, R.K. (2009), Case Study Research: Design and Methods, 4th ed., SAGE, Los Angeles and London.

Yoo, Y. (2010), "Computing in everyday life: a call for research on experiential computing", MIS Quarterly, Vol. 34 No. 2, p. 213.

\section{Corresponding author}

Pierluigi Rippa can be contacted at: pierluigi.rippa@unina.it

For instructions on how to order reprints of this article, please visit our website:

www.emeraldgrouppublishing.com/licensing/reprints.htm

Or contact us for further details: permissions@emeraldinsight.com 